\title{
A Formação do Aluno na Graduação em Psicologia pela Pedagogia de Paulo Freire
}

Paulo Freire's Educational Approach to the Student in the Undergraduation in Psychology

La Formación del Alumno en la Graduación en

Psicología por la Pedagogía de Paulo Freire
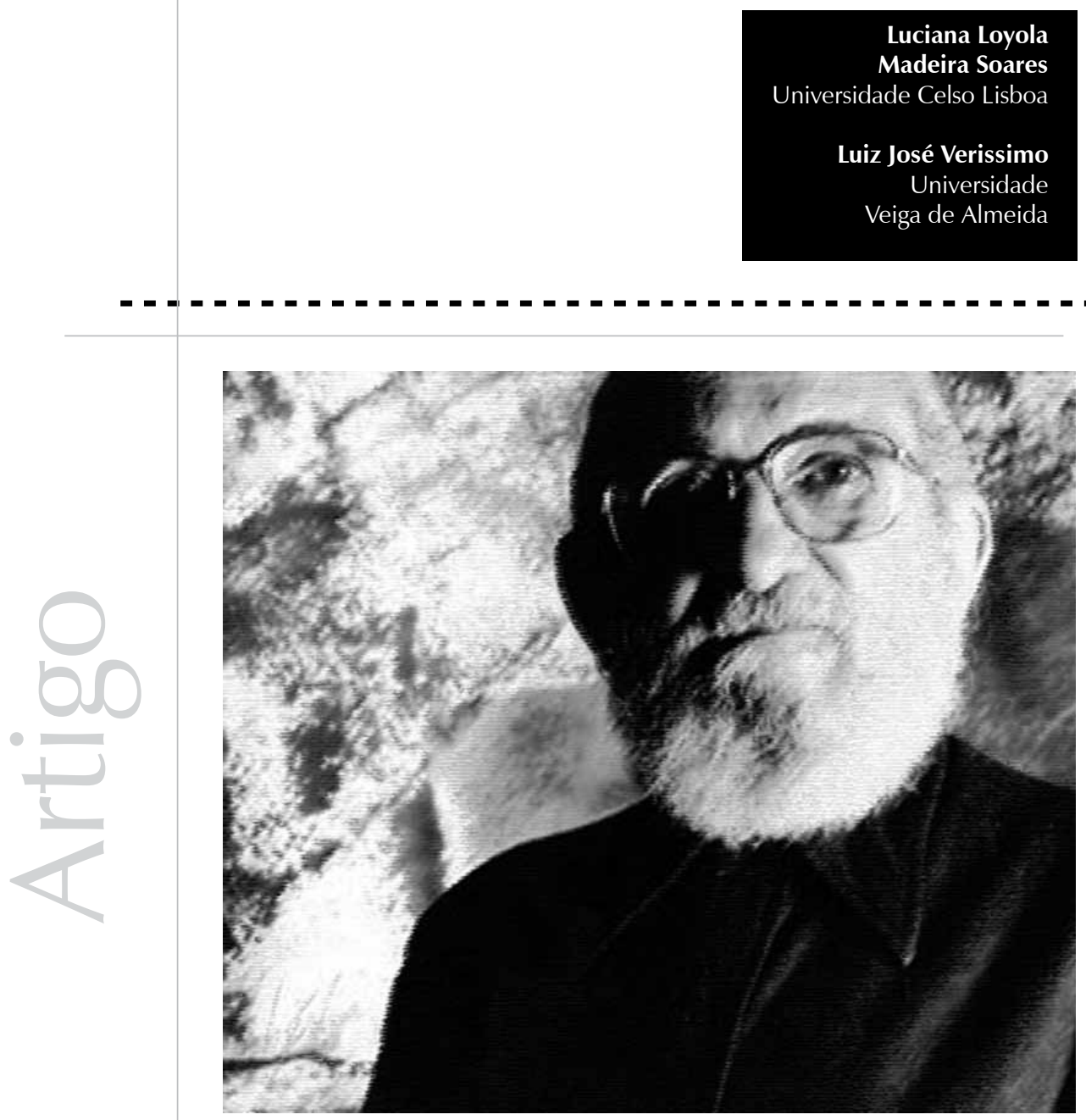
Resumo: O presente artigo consiste em um estudo teórico sobre os processos intersubjetivos na formação universitária do estudante da graduação em Psicologia. Consideramos a relação entre professor e aluno base formadora para a atitude ética do futuro psicólogo, entendido este como agente de transformação. Discutimos como os processos relacionais vividos em sala de aula entre professor e aluno propiciam a experiência transformadora e ética no próprio aluno por meio da afirmação e da confirmação de sua condição subjetiva. Tomamos a noção de produção de subjetividade em sua gênese a partir do encontro dialógico, e apresentamos a dialogicidade como recurso de intervenção do professor diante do contexto da formação universitária do estudante de Psicologia. Fizemos uma costura teórica entre diferentes autores, em uma interlocução que terá como eixo principal a perspectiva de educação libertadora proposta por Paulo Freire em sua abordagem dialógica.

Palavras-chave: Relação entre professor e aluno. Dialogicidade. Graduação em Psicologia. Educação libertadora.

\begin{abstract}
This work is a theorical work about the intersubjective processes that occur in classroom among the teacher and the students during the period of the undergraduation in psychology. Our purpose was to discuss how those relational processes interfere in bringing an ethic condition to the future psychologist as we considered this professional charged with the task of transformation. We indicated that subjectivity comes from the dialogical meeting in the relational processes during the undergraduation in psychology. We gave emphasis to the dialogical methodology as the most valid resource a teacher can have in classroom in the context of university. We proposed an interchange of speech among different authors in which Paulo Freire's educational dialogical approach was the center of the discussion.
\end{abstract}

Keywords: Relationship among teacher and students. Dialogical approach. Graduation in Psychology. Education for freedom.

Resumen: El presente artículo consiste en un estudio teórico sobre los procesos intersubjetivos en la formación universitaria del estudiante de graduación en Psicología. Consideramos la relación entre profesor y alumno base formadora para la actitud ética del futuro psicólogo, entendido éste como agente de transformación. Discutimos como los procesos relacionales vividos en sala de clase entre profesor y alumno propician la experiencia transformadora y ética en el propio alumno por medio de la afirmación y de la confirmación de su condición subjetiva. Tomamos la noción de producción de subjetividad en su génesis a partir del encuentro dialógico, y presentamos la dialogicidad como recurso de intervención del profesor delante del contexto de la formación universitaria del estudiante de Psicología. Hicimos una costura teórica entre diferentes autores, en una interlocución que tendrá como eje principal la perspectiva de educación libertadora propuesta por Paulo Freire en su abordaje dialógico.

Palabras clave: Relación entre profesor y alumno. Dialogicidad. Graduación en Psicología. Educación libertadora.

Muitos aspectos podem ser abordados no âmbito das relações entre professores e alunos, porém aqui faremos um recorte que privilegiará a discussão da relevância e da atualidade de considerarmos a presença do professor na construção do processo de ensino e aprendizagem especialmente no que diz respeito à formação do aluno da graduação em Psicologia. $\mathrm{O}$ estudo que ora apresentamos problematiza o cotidiano da formação acadêmica do psicólogo, tomando como referência o vínculo entre professor e aluno compreendido a partir da perspectiva dialógica tal como a encontramos em Paulo Freire. Discutiremos como esse investimento na relação com o outro repercute no aprendizado de tornar-se psicólogo. Nosso interesse pelo que se passa na graduação em Psicologia está ligado à nossa experiência de quase uma década como docentes nessa área. Entendemos a graduação em Psicologia como necessariamente tecida na rede de relações entre professores e alunos e entre os próprios alunos. Essa efetivamente é uma compreensão que vai muito além de se fazer um mero somatório dos conhecimentos teóricos e do acesso a ferramentas de cunho operacional e tecnicista para habilitar alguém que se candidata ao exercício da profissão de psicólogo. A perspectiva relacional será o viés para a experiência compartilhada de aprender, propiciando a transformação do 
Para Pegoraro (2005), "Ética é a busca permanente do sentido para a vida e para a história" (p. 24). passivo aluno-espectador em um sujeito com senso crítico e reflexivo, conforme postulou Paulo Freire, partidário que era da perspectiva dialógica em educação.

Observamos que, na universidade, o ensino assume algumas condições diferentes das praticadas na educação infantil, no ensino fundamental e no médio; já é suposto que os alunos apresentem uma bagagem de conhecimentos prévios, assim como um manejo próprio na maneira de aprender. De fato, o que observamos em nossa experiência como egressos da graduação em Psicologia e como docentes na área é que o aluno, ao longo de sua escolaridade (inclusive na instrução universitária), recebe informações que favorecem muito mais o adestramento que a autonomia, revelando uma feição educacional que tende mais à dependência do que à libertação. Nesse panorama, buscamos estudar as condições de investir em uma perspectiva menos sombria e mais alentadora, discutindo as possibilidades de reabilitar o caminho da criação e do espírito crítico juntamente à transmissão de conhecimento teórico e técnico na formação do futuro psicólogo, durante sua permanência como estudante da graduação, pelo viés da ética.

Com este artigo, trazemos um olhar sobre a formação acadêmica do psicólogo, propondo estudar o processo de aprendizagem do papel do psicólogo através da ativação da rede relacional que se forma entre alunos e entre professor e alunos na graduação em Psicologia. Focalizando a produção de subjetividade na graduação em Psicologia, apoiamo-nos no encontro dialógico como a fonte de onde emergem os sentidos que produzem a noção de ética do sujeito. Propomos o seguinte questionamento: em um curso de graduação cujo objeto de estudo seja justamente a produção de subjetividade, como se investe na vivência ética nas relações de sala de aula? O fato de encontrarmos somente nos últimos períodos da grade curricular uma disciplina denominada Ética Profissional revela que o curso abarca apenas um desenvolvimento instrumental da noção de ética. Destacamos que é importante a conscientização de que "a ética não é apenas procedimental como, sobretudo, destinada à existência do sujeito como um todo, e ao questionamento da mesma, com suas inevitáveis repercussões no dia a dia profissional?" (Veríssimo, 2008).

\section{A contribuiç̧ão da ética}

Para Pegoraro (2005), "Ética é a busca permanente do sentido para a vida e para a história" (p. 24). Segundo o autor, a ética é relacional, vale dizer, é constituída por uma reciprocidade interpessoal, indicando que ser ético implica, por assim dizer, posicionar-se em relação a alguém, não sendo necessário seguir regras para isso. A partir dessa noção, afastamo-nos das definições correntes de ética, que acabam promovendo uma confusão entre os campos da ética e da moral. A ética consiste no âmbito da reflexão sobre os valores vigentes e sobre a própria moral, enquanto a moral concerne às normas sociohistórico-culturais que os indivíduos adotam para si, assim como diz respeito às máximas subjetivas que os sujeitos elegem para decidir e avaliar suas ações, pautandose, em geral, no senso comum e nas suas experiências de vida. Ora, o campo a partir do qual podemos refletir é o da inter-ação humana, o campo de nossas relações, o campo intersubjetivo, enfim, a perspectiva relacional. Como diz Pegoraro, ninguém é ético somente diante do espelho. Ele observa que a ética é proveniente do pensamento de Sócrates, autor da máxima conhece a ti mesmo. Tal máxima representa uma árdua caminhada cheia de obstáculos pela qual o ser humano desenvolve as suas virtudes e, nos termos socráticos, torna-se senhor de si. Pegoraro, porém, convida-nos a considerar que não basta ser senhor de si, "pois ninguém é ético para si mesmo. Ninguém é virtuoso diante do espelho. Somos éticos em relação 
aos outros, visto que o comportamento é sempre transitivo e recíproco. Essa reciprocidade de comportamentos entre os seres humanos constitui a família, o grupo e a polis" (Pegoraro, 1997, citado por Hühne, 1997, p. 36).

Pelo que estamos examinando, podemos entender porque Pegoraro explicita ainda que normas regulam o exercício das liberdades, mas não consistem no nascedouro da ética, e que, portanto, o código disciplinar das profissões não pode (nem pretende) esgotar o horizonte dessa área.

Ao valorizarmos a dimensão dialógica da produção de subjetividade, a prática social da educação aqui será compreendida como a própria gênese da ética do sujeito. Por subjetividade, entendemos a busca da singularidade nos processos de sentido e de significação que apontam uma perspectiva multidimensional, rompendo, portanto, dicotomias e linearidades (Neubern, 2005). Consideraremos o sujeito ser ativo e criativo que, em sua condição de ser para a relação, possa manter relativa autonomia e realizar novas construções, reinventando caminhos na parceria educativa, rompendo padrões pré-moldados, onde sua autoria não aparece. A ética será considerada a pluralidade de possibilidades e impedimentos a que está exposto o sujeito desejante no decorrer de seu ciclo vital, ética entendida como o mosaico que se forma pela configuração da totalidade das diversidades humanas que se tocam e trocam em permanente processo de mutualidade, conforme Jurandir F. Costa (2000).

\section{Sobre as especificidades da produção de subjetividade e intersubjetividade a partir das relações em sala de aula}

Soares (2009) propõe que exibir-se como fonte de todo conhecimento revela uma inclinação do professor para a onipotência e a onisciência, e fomenta a formação de futuros profissionais supostos detentores do saber sobre o outro. De fato, o que sabe um professor sobre um aluno? Apenas sabe que não sabe sobre ele mais do que o próprio possa vir a saber. Ao dar espaço ao que não sabe, o mestre enseja abertura ao que o aluno não sabe, oferecendo-lhe assim a oportunidade de aprender sobre seu próprio modo de vir a conhecer. É uma aposta no desconhecer como melhor via de acesso ao conhecer e ao conhecer-se como sujeito da aprendizagem.

O professor oferece sua relação com o conhecimento; o encantamento do mestre com o seu peculiar aprender revela sua própria caminhada em direção a conhecer e a conhecer-se como sujeito da aprendizagem. Isso não significa tornar-se um modelo de aprendizagem para o aluno, mas pode servir de instigação para o aluno perceber seu próprio desejo de conhecer. Atento à alteridade, o professor cria uma abertura para receber o modo como o aluno aprende, encantando-se com a singularidade de seu aprender e favorecendo, assim, o encantamento do aluno com seu próprio aprender.

O professor aprende ensinando e ensina aprendendo - sobretudo aprende e ensina a partir da perspectiva de que é um permanente aprendiz de si mesmo, do outro e do modo como este aprende a conhecer. Ao dizermos isso, não insinuamos ingenuamente que o professor deva ser mais um aluno em sala de aula; a diferença de papéis e funções precisa estar claramente definida, pois a troca intersubjetiva só se dá em presença da alteridade. Naquele cenário passam diferentes histórias, diferentes experiências, diferentes conhecimentos, diferentes objetivos, diferentes projetos, diferentes aprendizados. A diferença é o que possibilita o encontro (Soares, 2009). 
Garcia (1989) é um educador que fundamenta suas idéias na obra de Paulo Freire e que nos oferece suas reflexões acerca da importância da relação professor/aluno nos cursos de formação de profissionais. Embora em seu texto o autor aborde especificamente a formação de professores, podemos articular suas idéias com as nossas quanto à formação de psicólogos:

Na relação pedagógica, o que se aprende não é tanto o que se ensina (o conteúdo), mas o tipo de vínculo educador-educando que se dá na relação.... O educando modifica suas atitudes (aprende) porque estabelece um vínculo com o educador e com o saber, como veremos; o caráter desse vínculo condiciona o caráter da aprendizagem. (p. 346)

Baseados nessa citação, afirmamos que, para ser psicólogo, não basta ter contato com os ensinamentos contidos na grade curricular, nas pesquisas acadêmicas, nas palestras e eventos dos quais participa, pois, se assim fosse, bastaria ler livros e passivamente assistir ao que se passa na universidade para tornarse psicólogo, e bem sabemos que não é o caso. Reiteramos que isso não condiz com a formação do psicólogo como agente de transformações. Ainda sobre o vínculo de aprendizagem, Garcia indica que:

Ora, o vínculo é, em princípio, de dependência, pois quem não sabe depende de quem sabe, mas, para completar o sentido autêntico desse vínculo, deve-se caminhar, começando por superar essa dependência, até culminar com a ruptura desse vínculo. A meta derradeira desse vínculo, repito, é fazer crescer, é conseguir que quem aprende não dependa de, é estabelecer um vínculo paradoxal cujo sentido profundo é atingido quando ele se rompe como tal, ou seja, quando o educador deixa de ser alguém de quem o aluno depende. (p. 347)

O autor prossegue, destacando que vínculos de dependência geram estereotipia, em vez de reflexão e criação, como na experiência compartilhada de conhecer. Concordamos com o autor quando afirma que a estereotipia estabelece a reprodução de repetidores de um modelo profissional formatado na noção de detenção de poder do conhecimento dos fenômenos psicológicos, sem compromisso com o fluir subjetivo. Concluímos que, na estereotipia, ficam engessadas as subjetividades por impedimento às trocas intersubjetivas. No trecho a seguir, o autor reafirma o valor do vínculo libertador:

é preciso ter em mente que a aula na aprendizagem libertadora é o vínculo, e não o conteúdo. Evidentemente este também tem sua importância, uma vez que o conhecimento cientificamente verdadeiro traz, em si mesmo, uma carga libertadora na medida em que nos revela as realidades físicas e humanas, individuais e históricosociais, mas essa carga atua com o tipo de vínculo que o educando com ele estabelece. (p. 352)

Por outro lado, devemos ponderar que a noção de aprendizagem como um acontecimento singular do sujeito não coaduna com a noção de autonomia se esta corresponder simplesmente à ideia de uma independência desvinculada do outro. A aprendizagem como experiência subjetiva e intersubjetiva envolve as noções de autonomia, heteronomia e mutualidade.

Cunha (2005) desenvolveu estudo sobre a constituição do papel e da função do professor a partir das noções de subjetividade e intersubjetividade no dia a dia da sala de aula. A autora afirma que as relações entre sujeitos "são social e historicamente organizadas, o que significa considerá-las como interação" (p. 200). Cunha valoriza a subjetividade nos papéis sociais que se estabelecem nos processos em sala de aula, dos quais não se pode excluir a presença de um sujeito para o outro em benefício dos conteúdos pedagógicos. "Consideramos que as relações sociais não envolvem apenas trocas objetivas; elas constituem um processo 
interativo no qual se destacam as relações inter e intrapessoais, que também poderíamos denominar subjetivas" (p. 197). Mais adiante, ela afirma que "os funcionamentos interpsicológico e intrapsicológico guardam entre si uma relação dialética, o que permite pensar a relação interintrapsicológico em termos de dialogia e da participação do outro na constituição do sujeito" (p. 203). Para a autora, a singularidade do processo de aprendizagem reside na interação, a qual produz subjetividade através da transformação de papéis e funções sociais em funções psicológicas superiores, conforme encontramos no seguinte trecho:

Constatamos também que a significação e a produção de sentidos são operações que fundamentam as experiências na sala de aula e que o professor, quando produz o seu trabalho ou fala de si mesmo, enfatiza aquelas questões que, em um determinado momento, são consideradas por ele como significativas, e por isso tais produções podem indicar uma síntese personalizada do processo social de constituição do sujeito. Podemos tomar, assim, o que é falado/ pensado/discutido/feito pelo professor em relação às condições de produção do cotidiano da escola e da sala de aula como indícios da constituição do sujeito. (p. 203)

Como conclusão do pensamento de Cunha quanto à ênfase nos processos de constituição de subjetividade, especialmente a partir do papel e da função do professor, citamos o seguinte trecho: "Por isso podemos dizer que a constituição do sujeito ocorre no dia a dia de diversas formas, combinando, de diferentes maneiras, consciência, afeto, reflexão e ações" (p. 204). E este outro:

A subjetividade constitui-se a partir de redes (relações) comunicativo-dialógicas que se estabelecem entre as pessoas; por isso, um estudo sobre professores não pode deixar de considerá-los como sujeitos e de buscar compreendê-los na relação com grupos e subgrupos da escola: os alunos e outros profissionais que participam diretamente da construção do dia a dia dessa instituição. (p. 210)
Dando sequência à linha de pensamento sobre a constituição de subjetividade a partir das experiências dialógicas em sala de aula, fomos buscar a contribuição de Tacca (2005). Essa autora enfatiza a importância de se compreender todo processo de aprendizagem através das relações que são estabelecidas em sala de aula. Encontramos, em diversos trechos do texto Relação pedagógica e desenvolvimento da subjetividade, sua convicção de que a aprendizagem se dá por processo de trocas intersubjetivas, e que a subjetividade se constitui e se reconstitui no sistema de interações do sujeito em seu contexto de relações. De acordo com a autora, não se pode dicotomizar o psiquismo em dimensão interna e externa, pois o sujeito deve ser considerado na expressão do seu sistema atual de interações e na história de suas interações. Assim, o processo de aprendizagem ocorre na interface do individual com o social, e só assim pode ser compreendido: como sentido subjetivo produzido na experiência intersubjetiva diante do objeto de conhecimento. Vejamos:

Podemos destacar a sala de aula e a escola como contextos precípuos de configuração da subjetividade, não somente pelo tempo que permanecemos neles, como pela força que sabemos ter em nós os amigos e os professores com os quais convivemos. (p. 216)

Nessa direção, o estudo da sala de aula pode esclarecer de que maneira as situações interativas são vivenciadas e como se tornam impactantes como circunstâncias de desenvolvimento dos sujeitos envolvidos no processo. (p. 217)

Tacca propõe que não há como apresentar e receber conteúdos pedagógicos sem vincular esse ato a uma troca intersubjetiva, na qual o que efetivamente faz a diferença, ou seja, o que propicia a transformação da informação em conhecimento pleno de significado é a interação entre os sujeitos 
do ensino-aprendizagem, daí o aluno vir a poder fazer algo com um conteúdo que passa a lhe pertencer e a operar sucessivas reconfigurações em sua percepção de si, do mundo e das relações que nele estabelece. A autora enfatiza que a relação professor-aluno é mutuamente marcada por intencionalidade, portanto, que encharca de valor simbólico e afetivo a objetividade dos conteúdos. É justamente nessa articulação que se dá a produção de subjetividade: "Ao acessar a parte objetiva do sentido, também se está acessando a subjetividade. Infere-se, assim, que, ao interpretar o objetivo, estamos também alcançando processos subjetivos" (p. 232).

Sobre os processos de ensino-aprendizagem, diz a autora: "As práticas formais de ensino mudariam consideravelmente se fossem consideradas como processos intersubjetivos, em que transitam, dinamicamente, os sentidos e os significados dos diferentes atores em sala de aula" (p. 235).

De fato, esse é um dos aspectos mais relevantes para nosso tema neste artigo, pois interessa-nos discutir, em termos do cumprimento dos propósitos educacionais, o quão fundamental para a formação do psicólogo é a experiência de mútuo significado a partir das relações vivenciadas nos processos de aproximação aos objetos de estudo durante a graduação.

Pensando no curso de Psicologia, a contribuição de Tacca se mostra efetivamente aplicada, na medida em que nos lembra que o sentido do que é transmitido somente emergirá enquanto se considerar a relevância do encontro de subjetividades, da malha intersubjetiva que se forma entre professor e alunos. Portanto, juntamente à transmissão do conteúdo pedagógico, é criado o sentido de papel e de função profissional, que cada aluno vai elaborar de maneira singular em sua experiência de aprender. De acordo com o que a autora frisa, só pode haver aprendizagem se dali brotar um sentido, o que, na graduação em Psicologia, significa que, ao lidar com o conteúdo pedagógico em sua vivência particular com o mesmo, o aluno presentifique a possibilidade de estar criando uma relação singular com a futura profissão.

Para isso, torna-se importante que, na sala de aula, sejam buscadas negociações de sentido entre alunos e professores, que são portadores de subjetividades únicas. Os conteúdos escolares, em si mesmos, somente alcançam seu potencial no desenvolvimento se estiverem revestidos de sentidos subjetivos para o aprendiz, podendo transformar-se em reguladores de ação individualizada e autônoma. (p. 237)

A educadora e psicopedagoga Fernández (1994) aborda de maneira interessante a importância do professor universitário na permissão ao aluno para o desejo de conhecer. Ela refere-se ao exibicionismo que pode acometer alguns docentes, fazendoos mostrarem-se como o próprio ideal de conhecimento diante de seus alunos, propiciando inibição ao desejo de conhecer. Vejamos:

Entre os professores universitários, acredito que essa modalidade esteja muito em moda. O ensinante exibe conhecimento, e o aluno, por tal razão, evita conhecer.

Esse é um conflito que cada um de nós, como professor, tem que resolver: aceitar que seus alunos possam aprender dele, porém sem idealizá-lo, sem considerar que sabe tudo.... O desejo de conhecer conectase com a angústia. Não há criatividade possível, se não há contato com a angústia, com a elaboração e a representação dessa angústia. Não há desejo de conhecer sem contato com o desconhecimento.... Mas, se aparece um ensinante que se posiciona como aquele que tem as respostas para todas as faltas, obviamente não haverá circulação do desejo de conhecer. (p. 162)

Ao perceber-se criando e recriando sua relação com o conhecer, o mestre não obstrui a visão do aluno na direção do conhecimento, 
e é precisamente isso que encanta o aluno: descobrir que pode encantar-se com sua singular caminhada rumo ao conhecer e conhecer-se, legitimando-se como sujeito da aprendizagem. A esse respeito, Fernández comenta sobre a impossibilidade de um docente interessado em motivar os alunos para aprendizagem pautar suas atividades em técnicas:

Não tenho uma técnica para resolver problemas. Tenho uma série de conhecimentos, de instrumentos. Se vejo cada situação como nova, como um desafio no qual encontro uma pergunta e uma resposta distinta, não há resposta prefixada que valha. A questão básica a considerar é uma mudança de atitude, não uma mudança de técnica.... Além disso, as técnicas são necessárias, mas não resolvem a questão. (p. 165)

Concordamos também com a autora quando ressalta que o professor precisa manter-se em humilde e permanente processo de revisão quanto à sua prática. Destacamos o papel essencial do professor na promoção de relações saudáveis ou, nem tanto, a partir de uma atitude que pode variar da permissão ao fluxo de afetos e de conhecimento, à omissão ou à centralização de poder e de saber. Essa variedade de atitudes nos permite vislumbrar o alcance da participação do professor na experiência do aluno que aprende a ser psicólogo: o que pode representar, na atuação profissional do psicólogo, aprender a centralizar poder e saber ou omitir-se? Por outro lado, se defendemos uma prática profissional pautada na ética, necessariamente estamos considerando um psicólogo que atua na afirmação e confirmação do outro como alteridade, sujeito de singularidade e de direito de expressão, sujeito na condição de falar por si como só ele mesmo poderá fazêlo (Soares, 2009).

Voltando a Garcia (1989), vemos que as funções de um docente comprometido com a educação libertadora seriam romper o estereótipo do vínculo dependente, mesclando diretividade com não diretividade, isto é, ter objetivos sem ser autoritário. Concordamos com essa abordagem, acrescentando que o docente deve instar os alunos a verificar seus próprios objetivos e o modo de lidar com os colegas, com o professor, com o conhecimento e com sua maneira de conhecer. Dessa forma, pretendemos favorecer no aluno uma revisão dos modelos já assimilados em contraste com a singularidade de seu propósito com a própria formação profissional. Garcia acrescenta ainda que cabe ao professor desvelar os ditos e os não vistos na dinâmica do grupo de alunos da turma; aproveitar falhas do tipo esquecimentos e equívocos de modo a estabelecer uma parceria com o processo de aprendizagem do aluno, a fim de que este possa ser estimulado à autonomia de estudar, pesquisar, refletir, duvidar, criticar, enfim, de manejar criativamente sua relação com o conhecimento; sinalizar os fenômenos relacionais e aproveitá-los para o aprendizado coletivo, sem, contudo, travesti-lo de intervenção psicoterápica, uma vez que o contexto escolar não comporta tal encaminhamento.

De acordo com Soares (2009) o assinalamento do professor é não diretivo, pois não tem o intuito de correção, mas o de sugerir que se perceba algo que ali está dando o sinal de sua presença. Nesse contexto, o grupo passa a poder dedicar-se à tarefa de aprender a ser psicólogo através de um vínculo/ parceria de construção coletiva a partir do encontro com a alteridade, uma vez que o professor entra em cena como um facilitador das experiências de conhecer pelo ato de conhecer-se como sujeito da aprendizagem.

Ao longo da docência, na memória dos professores, alguns alunos são lembrados em especial, devido à singularidade de sua participação no processo educacional; um ou 
outro traço de alguns alunos fica registrado devido a alguma situação específica que os tenha colocado em destaque diante do mestre. Pensando no que seria esse destaque, remetemo-nos a situações de encontro efetivo, nas quais haja maior proximidade favorecida pela mediação dialógica.

Sem receber a palavra do aluno, não há como o mestre conhecê-lo, não há como saber se participa de sua formação nem como identificar sua demanda. Em cada palavra dirigida ao mestre, há tanto um pedido quanto um oferecimento. Criase uma possibilidade de encontro de subjetividades - um evento intersubjetivo, que é exatamente o que aqui nos importa. O pedido e o oferecimento do aluno podem vir em forma de crítica, dúvida, equívoco, agradecimento, elogio, questionamento, competição, etc. O revestimento pode ser o tom agressivo, ácido, sedutor, bajulador, envergonhado, subserviente, ávido por conhecer, sinceramente interessado em aprender, entusiasmado, racional ou emotivo. Venha como vier, ali está o aluno se fazendo presente, ousando ir além da formação do passivo recebedor de ferramentas que o habilitarão tecnicamente. Mais que informação, ele solicita algo ao professor: minimamente ser percebido em sua singularidade, oferecendo-se subjetivamente em meio à massa de alunos da turma. É como uma carta de apresentação escrita de próprio punho.

Soares (2009) afirma que ao acolher esse pedido/oferecimento/apresentação, o docente estabelece uma validação daquele sujeito, medida que se alinhava ao dado objetivo da informação referente ao conteúdo pedagógico em foco. Pondo lado a lado a confirmação do sujeito e a investigação do conhecimento relativo ao conteúdo da disciplina, o professor encarna propriamente o regente, aquele que rege, integrando e harmonizando diferentes sons, vozes, tentando eliminar ruídos indevidos. O mestre pode reger a cena pedagógica transformando a sala de aula em um solo fértil para as experiências intersubjetivas do grupo, proporcionando a todos - aos alunos e a si mesmo - o criar-se e o recriar-se, tendo como mediação o conteúdo da disciplina.

Nesse solo fértil para a intersubjetividade que pode ser a sala de aula na graduação em Psicologia, não há como mestres e alunos se esquivarem do impacto que o conteúdo das disciplinas que envolvem o estudo dos fenômenos psicológicos provoca e evoca. Entendemos que esse impacto produz mobilizações imprevisíveis, revivescências, questionamentos, curiosidades e inquietações. Tudo isso cria as condições para aquecer a malha relacional tecida pelas implicações singulares dos sujeitos no processo acadêmico, tanto professor quanto alunos. Portanto, não há como separar cognição, afetividade e lado social no contexto educacional, especialmente no que se refere à graduação em Psicologia.

Segundo Soares (2009), desviar-se desses impactos é não reconhecer o espaço relacional acadêmico, em si mesmo, como um dispositivo formador pode constituir uma antiaprendizagem, ou antiensino, o que redunda em direcionar a universidade para o treinamento de técnicos que assumam o posto de responsabilidade pela reificação dos fenômenos psicológicos, de profissionais descomprometidos com a ação transformadora. Afinal, como aprender sobre subjetividade distanciando-se da troca intersubjetiva desde os bancos da universidade?

\section{A dialogicidade em educação - a pedagogia de Paulo Freire}

A pedagogia de Paulo Freire é essencialmente voltada para o camponês, para o operário, para todos aqueles oprimidos por estratégias de controle e submissão. Para ele, educar é uma tarefa inteiramente política e revolucionária, 
fundamentada na crença na dialogicidade como via de estabelecimento da libertação e da transformação. O reconhecimento da alteridade é o que cria a possibilidade do diálogo. A anulação das diferenças não permite diálogo; portanto, uma intervenção pedagógica pautada na obra de Paulo Freire é baseada na convicção de que o novo surge somente do encontro entre diferentes que apresentem uma disponibilidade mútua para a ação criativa.

Esse destacado pedagogo nordestino pretendia propiciar, com seu método de alfabetização, o alcance de uma leitura crítica das relações no mundo por parte do educando, em que ele pudesse sair da passividade para uma atitude transformadora a fim de se tornar um sujeito histórico. Sua preocupação era com o sujeito como parte de um contexto relacional grupal, não apenas em sala de aula mas também dentro de todo o contexto de convivência e de cultura que interfere na constituição de sua subjetividade e que é também por ele constituído.

O método pedagógico de Paulo Freire consiste na compreensão de que educar é permitir ao homem ser sujeito, agindo pela transformação do mundo através de relações de reciprocidade. Para ele, o objetivo da educação é provocar uma atitude crítica comprometida com a ação. O educando, portanto, aprende a falar falando, a agir, agindo e a transformar, transformando-se. A permanente possibilidade de transformação do aluno e do professor requer um ensino transformador e em transformação. Afinal, se nos baseamos em uma concepção de que a inconclusão, a incompletude do sujeito é o que permite a educabilidade, a educação não pode limitar-se a conteúdos fechados em si mesmos. "Isso obriga a uma revisão total e profunda dos sistemas tradicionais de educação, dos programas e dos métodos" (Freire, 2006a, p. 45).

Freire nos inspira a considerar a educação pela perspectiva do encontro dialógico, indicando o processo de ensino e aprendizagem como uma prática na qual tanto os alunos quanto o professor estão pessoalmente envolvidos no encontro pela palavra, sendo a vivência da mutualidade o próprio instrumento da aprendizagem e da produção de conhecimento.

Seu percurso como educador mostra uma dedicação singular ao processo: a cada relação com a turma, com cada aluno, age como se estivesse se deparando com a docência pela primeira vez, procurando o novo como novo, olhando com olhos de quem quer conhecer, e com a audição de quem quer efetivamente escutar.

A chamada Pedagogia do Oprimido, como ficou conhecida sua abordagem, propõe que o aluno passivo-recebedor, na educação bancária, passe a agente de transformação na prática da educação libertadora. O autor apresenta o educador-bancário como aquele que se volta para uma lida estritamente objetiva com os conteúdos pedagógicos. Já o educador-educando dialoga, problematizando o programa a ser trabalhado. Vejamos, segundo as palavras do próprio autor:

Somente o diálogo, que implica um pensar crítico, é capaz também de gerá-lo.

Sem ele, não há comunicação, e sem esta não há verdadeira educação.

Daí que, para essa concepção como prática da liberdade, a sua dialogicidade comece não quando o educador-educando se encontra com os educandos-educadores em uma situação pedagógica, mas antes, quando aquele se pergunta em torno do que vai dialogar com estes. Essa inquietação em torno do conteúdo do diálogo é a inquietação em torno do conteúdo programático da educação. (Freire, 1979, p. 98) 
Paulo Freire (2006b) defende a ideia de que o movimento crítico, reflexivo e dialógico que flui em sala de aula deve ser o ponto de partida para a ação, pois, praticando o reconhecimento da alteridade e o diálogo entre as diferenças desde a relação professor/ aluno e alunos/alunos, o estudante já está praticando a atitude revolucionária, em uma construção intersubjetiva, agindo pela transformação, que tanto se acha presente na perspectiva pessoal e singular do sujeito quanto nos diferentes grupos dos quais faz parte.

Na obra de P. Freire, há evidências de sua preocupação com o impacto do professor sobre o aluno:

A percepção que o aluno tem de mim não resulta exclusivamente de como atuo, mas também de como o aluno entende como atuo. Evidentemente não posso levar meus dias como professor a perguntar aos alunos o que acham de mim ou como me avaliam. Mas devo estar atento à leitura que fazem de minha atividade com eles. Afinal, o espaço pedagógico é um texto para ser constantemente "lido", interpretado, "escrito" e "reescrito". (Freire, 2006a, p. 97)

Se Paulo Freire (2006b) já afirmava a importância do compartilhamento dos educandos entre si e com os educadores de suas experiências, histórias e saberes, Madalena Freire (2008) aprofunda o olhar ao "resgate das lembranças da vida de aluno na sua relação com o educador, dentro da história de cada um" (p. 42). A autora assinala que este constitui o primeiro movimento dentro do processo relacional que é a aprendizagem:

Resgatar, salvar do esquecimento alienado as lembranças de nossa história pedagógica com nossos modelos é entrar em diálogo crítico com nosso passado, podendo assim, ajudar-nos, também, a entendê-lo, superá-lo, esquecê-lo, como ato consciente de quem perdoa. Muito diferente do estado de amnésia em que se encontrava anteriormente. (p. 42)

Paulo Freire (Amatuzzi, 1989) afirmava que a transformação por ele defendida só ocorre mediante dialogicidade, que envolve um profundo senso de união e de amor diante das diferenças entre os sujeitos - um fala com o outro; segundo ele, não há transformação se há dominação, ameaça ou submissão, pois, nessas condições, não há respeito às diferenças, portanto, não há dialogicidade - um falar para o outro. Madalena Freire (2008) acredita que aprendizagem e ensino só ocorrem mediante afetos como amor e ódio, nunca mediante a indiferença, pois não somos dotados apenas de cognição. Para ambos, não há qualquer hipótese de neutralidade em educação, donde podemos valorizar a perspectiva da produção de subjetividade como fundamental para considerar a gênese da ética nos processos educacionais. Sem reconhecimento das diferenças, não há efetivo encontro pela palavra, portanto, não emerge a pluralidade de possibilidades de onde brota o senso de ética. Segundo Paulo Freire, defender a neutralidade em educação é retirar professor e alunos da condição de sujeitos, esvaziando as relações em sala de aula (Freire, 2006b, pp. 97-99).

O reconhecimento dos diferentes afetos que surgem em sala de aula pode ser uma tentativa de estabelecer um diálogo com o mestre; no entanto, se este mantiver o aluno refém desse amor/ódio, em uma atitude de conservar a idolatria ou a repulsa à sua superioridade, ao seu saber e ao seu modo de conhecer, arrisca-se a manter o aluno cativo do desejo de ser como ele (mestre), de falar como ele, de saber como ele. De acordo com a perspectiva bancária denunciada por Paulo Freire (1979), assim fica o mestre 
no lugar de opressor e o aluno no lugar de oprimido; não estará criando a dialogicidade nem permitindo que a palavra própria emirja. Não se pode esperar transformação, nesse caso, e, sim, repetição. Ousamos afirmar que esse modelo estático e engessado de relação deforma alunos, exclui a compreensão e os conserva sujeitos sem palavra própria e sem conseguir manejar seu desejo de aprender e de produzir seu saber. Em Amatuzzi (1989) encontramos uma reflexão baseada na obra de Paulo Freire: "O educador dialógico... propõe (não impõe)" (p. 82), pois sabe que tem a função de contribuir para uma efetiva transformação das relações no mundo.

De acordo com Soares (2009), ao olhar o aluno com olhos de quem quer conhecer, o professor dirige-se ao modo como ele, em sua singularidade, aprende naquele grupo. Entendemos que essa seja uma atitude que favorece o aluno a perceber para onde dirige seu olhar. Pela afetividade a si dirigida, o professor pode encantar o aluno com seu modo de conhecer, levando-o pela dialogicidade a encantar-se em descobrir seu próprio modo de vir a conhecer produzindo conhecimento. Acreditamos que o aluno fique assim habilitado a fazer uma leitura crítica do mundo ao fazer uma leitura crítica das relações em sala de aula, ampliando também sua experiência amorosa na relação com o mundo.

Em se tratando neste artigo dos aspectos entre professores e alunos na graduação em Psicologia, indicamos que a reflexão sobre a aplicação da metodologia pedagógica de Paulo Freire seja especialmente proveitosa, se na universidade estamos formando profissionais da escuta, da atenção, da compreensão, comprometidos com a transformação e capacitados a contribuir para que outros sujeitos resgatem a condição de pronunciar sua própria palavra. Quando o professor se considera formado, transmite ao aprendiz a noção de que em breve ele também estará formado, no sentido de estar pronto, o que encerra as possibilidades de fomentar o permanente desenvolvimento. Portanto, se assim for, estar formado é o que o aprendiz mais deseja, o que o insere em uma rotina de buscas pelo que já possui uma forma definida e delimitada.

Como Paulo e Madalena Freire têm na educação seu compromisso, colhemos suas contribuições sem o risco de estarmos aventurando-nos em uma proposta de psicoterapia em sala de aula. A intervenção desses educadores visa à práxis, ou seja, a propiciar novas ações, novas atitudes. De acordo com o próprio Paulo Freire (2006a):

Minha presença de professor, que não pode passar despercebida dos alunos na classe e na escola, é uma presença em si política. Enquanto presença, não posso ser uma omissão, mas um sujeito de opções. Devo revelar aos alunos minha capacidade de analisar, de comparar, de avaliar, de decidir, de optar, de romper. Minha capacidade de fazer justiça, de não faltar à verdade. Ético, por isso mesmo, tem que ser o meu testemunho. (p. 98)

A manifestação dos afetos dirigidos pelo aluno a seu mestre indica a não neutralidade dos processos educacionais. O aluno como sujeito ali se manifesta em uma de suas primeiras ações no ambiente de sala de aula. O modo como o professor identifica, acolhe e maneja essa afetividade também não é neutro, pois depende de sua atitude ética para reconhecer que constitui o território da intersubjetividade. Do trabalho desse grande mestre nordestino, podemos entender que a ação educativa parte de uma relação de heteronomia (na qual o aluno espera tudo 
receber de seu professor) para a autonomia (na qual o aluno se liberta ao aprender e produzir conhecimento). No entanto, isso não é suficiente para uma efetiva emancipação. Se o aluno se liberta do molde pela experiência dialógica, então vislumbramos uma dimensão que não pode ser definida nem como estreitamente dependente nem como estritamente independente. Estamos diante de uma concepção educativa eminentemente ética, que brota das trocas intersubjetivas e que a elas estará atrelada. Para Paulo Freire (2006b), a prática docente é, necessariamente, profundamente ética, pois traz como exigência a interlocução entre as diferenças. Toda manifestação em sala de aula precisa, segundo ele, ser acolhida, lida e tratada pelo diálogo entre as alteridades. Isso é bem diferente da "ética de mercado", que preconiza o fatalismo, a competitividade como opção única, as vantagens pessoais; é a "ética universal do humano" (p. 15) que nos interessa, aquela que abarca a diversidade das possibilidades humanas.

Soares (2009) apresenta a ideia de que, sem essa ética, a formação do psicólogo perde sua característica de movimento de contracultura e de valorização de relações repletas de conteúdo de memórias e de afetos. Seguindo nessa linha de pensamento, acreditamos que as chamadas leis de mercado não devem impor ao estudante uma formação com ênfase nos aspectos técnicos em detrimento de uma proposta de reflexão sobre sua condição de sujeitos sociohistóricos, dotados de histórias, afetos e sonhos pessoais.

Pretendemos, como Paulo Freire, resgatar a sabedoria dos que pensam não saber. Ao considerarmos a relação professor/aluno na graduação em Psicologia na perspectiva da Pedagogia do Oprimido, destacamos alguns pontos que podem caracterizar o que oprime o aluno: ser mais uma cria de um sistema educacional universitário opressor e tecnicista, com a visão de uma prática profissional elitizada e elitizante.

Paulo Freire (2006b) recomenda que não esqueçamos que faz parte da atitude ética do educador estabelecer um diálogo entre autoridade e liberdade, ou seja, saber manejar o conhecimento tácito e indispensável e tudo que pode ser questionado e criado a partir do mesmo pela própria experiência do aluno. Sua sugestão (Freire, 2006a) é a de uma pedagogia que emane da relação entre professor e alunos. Defendemos a ideia de que o que importa na graduação em Psicologia, especialmente por sua condição de formar futuros agentes de transformação, é o trabalho pedagógico erguido sobre pilares relacionais.

De fato, não bastam a leitura e a memorização de textos teóricos e técnicos para aprender a ser psicólogo; conforme Paulo Freire (2006b) enunciou sobre a insuficiência do conteúdo para a formação de um aluno: "Repete o lido com precisão, mas raramente ensaia algo pessoal. Fala bonito de dialética, mas pensa mecanicistamente" (p. 27). Acreditamos na urgência de indagarmos se, na graduação em Psicologia, estamos alfabetizando estudantes para habilitá-los a uma leitura crítica e afetiva das relações das quais participa, de modo a favorecer que venham a proferir sua própria palavra e, a partir disso, a favorecer a ampliação da percepção e da compreensão. É questionável formar futuros psicólogos que, na Academia, só aprenderam a falar a palavra do enquadramento disciplinar que trazem consigo. "Sujeito alienado do próprio pensamento torna-se mero repetidor da teoria dos outros" (Freire, 2008, p. 72). Concordamos com a autora quanto ao fato de que, para formar um profissional autor de seu pensamento, é necessário resgatar o que 
ele já sabe, pensa e reflete a partir de sua bagagem pessoal e de sua vivência no grupo em sala de aula e com seu mestre, juntandose a isso o oferecimento de informação teórica simultânea ao acompanhamento de sua reflexão. Entendemos, portanto, que, especialmente na graduação em Psicologia, os processos pedagógicos são indissociáveis dos relacionais.

\section{Considerações finais}

No contexto da graduação em Psicologia, podemos verificar que o encantamento do aluno para com seu mestre pode ser uma fase do processo de aprendizado, mas sem a perspectiva de benefício em sua manutenção. Ao perceber e acolher a diversidade de possibilidades do investimento afetivo que Ihe é dirigido, o mestre permite que o aluno experimente sua própria alteridade em relação ao outro, podendo aprender a lidar com suas próprias condições e recursos antes engessados pelo encantamento, mas agora disponibilizados. Apontamos um aprendizado para a autonomia de pensamento e de ação enfatizando, no entanto, que, dialeticamente, o aprendizado da autonomia se apóia na heteronomia, já que a noção de desejo, da falta, do vazio, o desconforto de saber-se incompleto desembocam na busca pela completude, na busca pelo outro (o professor, os colegas), enquanto parceiro(s) para a experiência compartilhada do aprender sobre si, sobre o outro, sobre o mundo. Ao lidar com o emergente em sala de aula, é possível ensinar e aprender sobre si mesmo em uma construção intersubjetiva. As interrogações e interpelações dos alunos no cotidiano educacional indicam o caminho para que o professor conduza os processos relacionais em sala de aula de modo a fazer com que cada aluno se interrogue sobre o que quer e precisa saber, sobre o sentido de sua busca, sobre o conhecimento que está obtendo e sobre o que está fazendo para viabilizar seu próprio aprendizado. É a maneira criativa de ensinar a aprender a manejar a experiência de conhecer.

Assim, sinalizamos a importância de o professor colocar-se para os alunos como um preceptor: aquele que os precedeu, mas que não conhece o final do caminho por não ter chegado lá, e que sabe que nem ele nem ninguém mais chegarão. $\mathrm{O}$ mestre de futuros psicólogos pode ser descrito como aquele que não concluiu o saber, que não dispõe de fórmulas de sucesso nem de garantias de apaziguamento, porém, o mestre pode lidar com o que emerge a cada situação, reconhecendo as alteridades, fazendo parte de um aprendizado e de um crescimento coletivos. Entendemos que isso é a própria ética indispensável na formação acadêmica do futuro psicólogo.

Ressaltamos que educar é possibilitar a transformação sem impedi-la; inicialmente, faz parte da habilidade do professor perceber o encantamento do aluno pelo modo como o mestre se encanta com o conhecer, porém, não tornando o aluno refém do narcisismo do próprio mestre. Defendemos uma prática pedagógica libertadora em que o professor permita que o aluno, conhecendo-se através de sua busca pelo conhecer, se encante com sua maneira singular de aprender e de produzir conhecimento e, assim, transformese e torne-se, como profissional, um agente de transformação. 


\section{Luciana Loyola Madeira Soares}

Mestre em Psicanálise, Saúde e Sociedade pela Universidade Veiga de Almeida, Rio de Janeiro - RJ - Brasil.

Luiz José Verissimo (Universidade Veiga de Almeida)

Doutor em Filosofia pela Universidade Estadual do Rio de Janeiro, Rio de Janeiro - RJ - Brasil.

E-mail: filosjverissimo@yahoo.com.br

Endereço para envio de correspondência:

Rua José Higino no 282 AP. 101- Tijuca, Rio de Janeiro - RJ - Brasil CEP 20520-202.

E-mail: psi.lucianasoares@gmail.com

Recebido 04/5/2009, 1프 Reformulação 16/8/2009, 2ª Reformulação 25/11/2009, Aprovado 09/12/2009. 


\section{Referências}

Amatuzzi, M. M. (1989). O resgate da fala autêntica. Filosofia da psicoterapia e da educação. Campinas, SP: Papirus.

Costa, J. F. (2000). A ética e o espelho da cultura. Rio de Janeiro: Rocco.

Cunha, M. (2005). Subjetividade e constituição de professores. In F. Gonzáles-Rey (Ed.), Subjetividade, complexidade e pesquisa em psicologia (pp. 191-213). São Paulo: Pioneira Thomson Learning.

Fernandéz, A. (1994). A mulher escondida na professora. Uma leitura psicopedagógica do ser mulher, da corporalidade e da aprendizagem. Porto Alegre: Artmed.

Freire, M. (2008). Educador, educa a dor. São Paulo: Paz e Terra.

Freire, P. (1979). Pedagogia do oprimido (7a ed.). Rio de Janeiro: Paz e Terra.

Freire, P. (2006a). Conscientização - teoria e prática da libertação (3a ed.). São Paulo: Centauro.

Freire, P. (2006b). Pedagogia da autonomia (34a ed.). São Paulo: Paz e Terra.

Garcia, G. (1989). A relação pedagógica como vínculo libertador. Uma experiência de formação docente. In M. H. S. Patto, Introdução à psicologia escolar (pp. 342-360). São Paulo: T. A. Queiroz.
Neubern, M. S. (2005). A subjetividade como noção fundamental do novo paradigma: breve ensaio. In F. Gonzáles-Rey (Ed.), Subjetividade, complexidade e pesquisa em psicologia (pp. 53-79). São Paulo: Pioneira Thomson Learning.

egoraro, O. A. (1997). Ética e seus paradigmas. In L. M. Hühne (Ed.), Ética (pp. 25-67). Rio de Janeiro: Uapê.

Pegoraro, O. (2005). Introdução à ética contemporânea. Rio de Janeiro: Uapê.

Soares, L. (2009). A relação entre professor e aluno na graduação em psicologia: a importância dos processos intersubjetivos e dialógicos na formação universitária. Dissertação de Mestrado, Universidade Veiga de Almeida, Rio de Janeiro, RJ.

Tacca, M. C. (2005). Relação pedagógica e desenvolvimento da subjetividade. In F. Gonzáles-Rey (Ed.), Subjetividade, complexidade e pesquisa em psicologia (pp. 215-240). São Paulo: Pioneira Thomson Learning.

Verissimo, L. J. (2008). Introdução ao estudo da ética. Rio de Janeiro: Universidade Veiga de Almeida. (Material didático (e anotações de aula) da disciplina Ética Profissional, do Curso de Graduação em Psicologia) 